\title{
ENHANCEMENT OF PUBLIC ACCOUNTABILITY FINANCIAL REPORT OF THE PUBLIC AREA - REALITY AND RECOMMENDATIONS
}

\author{
CAO THI CAM VAN, TRUONG A BINH \\ Industrial University of Ho Chi Minh City; \\ tqvan1611@gmail.com,truongabinh@gmail.com
}

\begin{abstract}
The reform of the public accounting system towards financial transparency and the enhancement of public accountability is an inevitable trend of most countries in the process of economic integration, in Vietnam, after 10 years in implementation of the public financial management reform project, the Vietnam public sector has also achieved significant achievements in financial management, especially public sector accounting information, which has been increasingly publicized, more transparent, people's confidence in the State as well as State agencies is strengthened. However, it is undeniable that Vietnam's public accounting system is still limited, inadequate, information provided by the public accounting system has not improved the accountability of State agencies, and the violations in State budget management still exist. Enhancement ofpublic accountability of Vietnam State agencies is not only an urgent requirement from the national situation to effectively manage and use budget resources but also the requirements of economic relations through the integration process. Therefore, this article mainly explores in depth the factors affecting the accountability of financial reporting of the units public sector in Vietnam, thereby measuring the impact of factors, proposing appropriate solutions and policies to promote the accountability of public agencies in State budget management.
\end{abstract}

Keywords. Public accountability, public accounting system, financial report, public area.

\section{INTRODUCTION}

Vietnam's public financial reform and renovation of the public sector accounting system have achieved many remarkable achievements over the years, information on public financial situation through financial statements has been increasingly publicized, and people's right to approach public financial information is gradually acknowledged. However, in the process of operating the public accounting system, it has revealed many shortcomings, the accountability of financial reports of State agencies has not been put into consideration, the violations inState budget management process are quite common, and one of these main causes is limitation in assessing the responsibilities of State agencies. Therefore, the Resolution of the Party Central Committee Conference fifth meeting (XIIterm) emphasized the orientation in completing the monitoring mechanism, improving publicity, transparency and enhancing the accountability of State agenciesin State budget management. With the desire to contribute to the development of solutions to enhance the accountability of State agencies in State budget management, this study will explore and measure the factors affecting the implementation of Vietnam's public sector financial reporting accountability, thereby supporting experts and policy makers in government financial management.

\section{THE THEORETICAL BASIS OF THE STUDY}

\subsection{Necessity to enhance accountability of financial reports of State agencies in State budget management}

It is no coincidence that public accounting reforms in many countries focus on enhancement of public accountability, and consider this a key task in economic development, for Vietnam, at Decree No. 90/2013/ND-CP issued by the Government on August 8, 2013 "Explanation means the provision for, interpretation and clarification of information conducted by state agencies about implementation of their assigned duties and powers and responsibilities in implementation of such duties and powers."The 
requester for explanation include agencies, organizations and individuals who request state agencies, competent persons for explanation about contents related to implementation of their rights and obligations. The explaining persons include heads of state agencies or persons authorized by heads of state agencies for implementation of explanation. The focus of this matter is always the mutual supervision between organizations to ensure the responsibility of each individual, each organization for their daily tasks of data on financial reports.

Meanwhile, accountability has a close relationship with financial transparency [17] that impacts and reinforces each other, the combination of transparency and accountability that helps improving the quality of decisions in the public sector, making policies more effective as a driving force for private sector activity. Therefore, improving accountability of public finance is important for promoting effective management, exploiting the national economic potential and strengthening public trust.

\subsection{Overview of accountability for public sector financial reports}

Definition.According to UNDP and the Organization for Economic Cooperation (OECD), accountability requires three main pillars:(i) Transparency: Citizens have the right to access information related to commitments that the government has issued (ii) Accountability: Citizens can ask the government to respond to their activities (iii) Validity: Citizens can punish if the government violates the standards of commitment. According to the Community Sector Council, "accountability is the ability to explain the actions of an object or an organization's representative, often used to demonstrate ways of how the funds are used by employees." Nguyen Si Giao (2013) [14] said accountability is the responsibility of the authorized person to perform the task before the authorizer including: (i) The responsibility to provide full and accurate information about the process of performing the assigned task; (ii) Responsibility for reporting, explaining and demonstrating the results of the assigned tasks and (iii) Responsibilities for the performance of the tasks.

Role. According to Hulme\&Sanderatne (2008) [14], if considering both private and public sector, accountability has the following roles: (i) provide information on the activities of National Assembly, Government, authorities, departments and mandated agencies (ii) affirm the responsibility of explaining person (iii) provide a reasonable explanation of responsibilities and powers, as well as those owning resources to perform tasks (iv) ability to take responsibility of the explaining person.

Content. According to Goetz and Jenkins (2005) [11], accountability is expressed in two basic contents, namely answerability and enforceability. According to Bovens (2007) [3], these two basic contents are presented in terms of accountability: organizational accountability; political accountability; legal accountability; professional accountability.

\subsection{Factors affecting the accountability of financial reports in public sector}

Summarizing the results of previous studies, there are many factors influencing the accountability of public financial report, which includes:

Political factor.Many studies agree that political competition such as running for public agencies, conflicts of interest between benefit groups, corruption, influence from political institutions, parliamentary supervision or support from executive and legislative agencies have a significant impact on public accountability[25,29].

Legal factor.According to some researchers, effects from the application of new public management model NPM [16,26] or apply the model of State General Accounting, developing Public Accounting Standards [19] has a significant influence on improving the accountability of public financial reports. At the same time, the influence of the legal compliance of agencies and implementing organizations [1], the coordination between departments, legal systems on accountability is tightly set up as shown in the document on information disclosure [6], developing uniform standards to assess the quality of financial reports in public sector are legal factors affect the accountability of public financial reports $[25,29]$. 
Economic factor.The Government's financial situation, the level of subsidies among localities are economic factors affecting accountability of public financial reports [21,29].

Socio-cultural factor. Researchers also demonstrate that the moral qualities of cadres and civil servants in the process of performing tasks affect the accountability [6,10]. In addition, people's educational level and the need to access government financial information are cultural and social factors that significantly affect the accountability of public financial reports $[25,29]$.

Education and career factor. Regarding the educational and occupational assessment, many experts agreed on the Internal Control [15,27]. Information organization system [18] Quality of State Audit [12] facilitating people to accessinformation [13], Decentralization, empowerment, organizational structure, and management are vocational education factors that significantly impact the public [13].

\section{RESEARCH METHODS AND RESULTS}

\subsection{Research method}

The author uses a combination of qualitative research methods and quantitative research methods. In particular, for the qualitative research method, the authors use the system approach; method of synthesis, analysis, comparison; objective reasoning method to identify and clarify factors affecting public accountability. For quantitative method, the authors use a combination of methods such as descriptive statistics, EFA factor discovery, regression analysis to test hypotheses and measure the influence of factors.

Subjects of the survey: Including experts, managers and accountants in the public sector and lecturers.

Survey results: 190 issued votes, 182 valid returns

Proposed research model:

$$
Y C=\propto+\beta_{1} C T+\beta_{2} P L+\beta_{3} V H+\beta_{4} N N+E i(1)
$$

In which: Political system (CT); Legal system (PL); Social culture (VH); Vocational education (NN)

\subsection{Research results}

a. Perform descriptive statistics. Describe a variable to determine the proportion of respondents, thereby considering the relevance of the research sample.

Describe the same scale variables, through the use of SPSS software to create tables containing descriptive statistical values. By observing the average value of each factor, the author determines the level of consent of the survey subjects based on the 5-level Likert scale.

Implementation of factor analysis model including: Quality control scale; KMO test and Bartlet accreditation; Testing the explanatory level of the observed variables.

b. Multiple regression models. Standardized regression model with regression coefficients by descending level as follows:

$Y C=0.499 C T+0.423 P L+0.413 N N+0.305 V H+19.077(2)$

\section{c. Testing the relevance of the model}


Table 1 . The result of the $\mathrm{R}^{2}$ coefficient value has been adjusted

Model Summary ${ }^{\text {b }}$
\begin{tabular}{|l|l|l|l|l|}
\hline Model & R & R Square & $\begin{array}{l}\text { Adjusted } \\
\text { Square }\end{array}$ & $\begin{array}{l}\text { Std. Error of the } \\
\text { Estimate }\end{array}$ \\
\hline 1 & $.830^{\mathrm{a}}$ & .689 & .682 & .56388887 \\
\hline
\end{tabular}

a. Predictors: (Constant), VH, PL, NN, CT

b. Dependent Variable: YC

In Table $\mathrm{R}^{2}$, the adjusted value is 0.684 meaning that about $68.4 \%$ of the requirements explained by the 4 independent variables are political system, legal system, social culture and vocational education.

\section{d. Testing regression coefficients}

Table 2. The result of coefficients

\begin{tabular}{|c|c|c|c|c|c|c|c|c|c|c|}
\hline \multicolumn{11}{|l|}{ Coefficients $^{\mathrm{a}}$} \\
\hline \multirow[t]{2}{*}{ Model } & \multicolumn{2}{|c|}{$\begin{array}{l}\text { Unstandardized } \\
\text { Coefficients } \\
\end{array}$} & \multirow{2}{*}{\begin{tabular}{|l} 
Standardized \\
Coefficients
\end{tabular}} & \multirow[t]{2}{*}{$\mathrm{t}$} & \multirow[t]{2}{*}{ Sig. } & \multicolumn{3}{|c|}{ Correlations } & \multicolumn{2}{|c|}{$\begin{array}{l}\text { Collinearity } \\
\text { Statistics } \\
\end{array}$} \\
\hline & B & \begin{tabular}{|l} 
Std. \\
Error
\end{tabular} & & & & $\begin{array}{l}\text { Zero- } \\
\text { order }\end{array}$ & Partial & Part & Tolerance & VIF \\
\hline (Constant) & $1.379 \mathrm{E}-017$ & .042 & & .000 & 1.000 & & & & & \\
\hline PL & .423 & .042 & .423 & 10.091 & .000 & .423 & .604 & .423 & 1.000 & 1.000 \\
\hline $1 \mathrm{NN}$ & .412 & .042 & .412 & 9.829 & .000 & .412 & .594 & .412 & 1.000 & 1.000 \\
\hline $\mathrm{CT}$ & .497 & .042 & .497 & 11.849 & .000 & .497 & .665 & .497 & 1.000 & 1.000 \\
\hline VH & .306 & .042 & .306 & 7.308 & .000 & .306 & .481 & .306 & 1.000 & 1.000 \\
\hline
\end{tabular}

a. Dependent Variable: YC

All Sig values $<0.05$, so with $95 \%$ confidence and descriptive statistical results, the author concludes that 4 variables $\mathrm{CT}, \mathrm{PL}, \mathrm{VH}, \mathrm{NN}$ are correlated with the variable $\mathrm{YC}$, and the VIF values are even $<10$, indicating that there is no linear multipath phenomenon i.e there is no linear relationship between variables.

\section{e. Analyzing factors affecting to accountability for public financial reporting}

Political system factor: Considering the political institutions, it can be seen that democracy in our political institutions has not been promoted properly, people mainly show their aspiration through the People's Council but not directly express their opinions or expectations to the State.

In recent years, despite many innovations in the State financial management mechanism, the stagnation in the public sector is still existed, discouraging the initiative and creativity in the work, the management apparatus of the area, cumbersome, overlapping public areas affecting the efficiency of State operations. The National Assembly's supervision also has some certain limitations, in particular some reports addressed to the National Assembly, especially the financial reporting, the State budget finalization report is slow, not ensured the deadline as prescribed by law, as a consequent, limited time for National Assembly to study and carefully review the reports. The monitoring of legal documents in some cases has not been properly concerned, sometimes not going into the specific contents of each document, mainly focusing on the promulgation schedule, number amount of legal documents. 
Legal system factor: Considering the legal system of accountability in financial reporting, it can be seen that in recent years a series of legal documents on accountability are specified as Article 28 of the 2014 Constitution, Article 13 in Law on Complaints, Article 15 and Article 32a in Anti-Corruption Law 2013, Decree 90/2013/ND-CP prescribes on conditions to receive request for explanation, rights and obligations of requester for explanation and the person conducting explanation, however, the above listed documents are quite general, not really affecting the enhancement of accountability.Furthermore, to take measures to handle cases of violations on December 19, 2013, the Government issued Decree 211/2013/ND-CP amending and supplementing a number of articles of the Government's Decree No.107/2016/ND-CP, regulations on handling responsibilities of heads of agencies, organizations and units for corruption occurring in their agencies, organizations or units under their management and responsibility. However, blaming responsibility for heads is not simple, in practical, only people holding high positions and powers is enable for corruption and wastefulness. In addition, the current mechanism of management and use of cadres needs to be reconsidered in order to be able to account clearly and specifically for the head, to avoid "hiding and avoiding responsibility"of the head of the organization. Subsequently, Decree No. 25/2017 / ND-CP prescribes contents of 4 State financial reports in public, this is considered as a significant improvement in the financial statement explanation, but this work is not highly efficiency due to limited communication and awareness of people.

In term of evaluation of the Vietnamese public accounting system, many studies show that existences from the public accounting system including the current public sector include many different accounting regimes, making difficult for each level of management. Although, currently TABMIS systemis available to integrating the Treasury - Tax - Customs accounting system, this system is still incomplete, some shortcomings exist that affect the quality of public sector accounting.

Moreover, at present, the administrative and non-business units in Vietnam use two types of accounting facilities in parallel to record and report the operations arising in the State's activities and business and production activities in the units and in the real world. This situation has caused many complications, the financial statements have not been agreed yet, although the State has issued Circular 107, however, this is a new document that has been put into implementation and cannot be evaluated effectively. In order to uniformly manage public finance and the public accounting system, Decision No. 1188 / QD-BTC of the Ministry of Finance approved the project to build the General State Accounting to unify the financial management of the country and publicity and transparency of State financial information, so far, many reforms implemented by the State Treasury have been implemented as interbank payment integrated with TABMIS. However, in the coming time, there are still many difficulties and specific challenges of Decree 25 on the State Financial Statements are just the beginning of the State Financial Report, this is a new field so It is difficult both in terms of expertise and implementation, in order to achieve the goal by 2020, the State Treasury implemented the General State Accounting which is not easy, needing the constant coordination and efforts of the State as well as the sector relate to. In addition, the requirement to build Vietnam's public accounting standards has been set for a long time, but this has encountered some difficulties such as: the specific conditions of public accountants in Vietnam are much different from the standard. International public accounting, the cost of implementing uniform conversion of a system of financial statements on the basis of cash accounting proceeds to move to a large accrued accounting base, so it takes many years to realize show.

Professional education factor: Currently, the development of an internal control system is not a compulsory regulation for State management agencies, it is unavoidable for loss, embezzlement and waste occur in public agencies, moreover, public financial report without strictly internal control of accounting units certainly cannot provide reliable information.In addition, assessing the skills and qualifications of accounting officers and civil servants working in the public sector shows that many of these senior accountants have a reluctance to innovate, and work based on experience, the handling of accounting operations following new requirements is quite embarrassing, in many cases the accounting operations are not handled appropriately, do not reflect the nature and making certain influence on the data of the accounting period, the financial reports then reflect incorrectly the actual situation of the unit 
causing difficulties in assessing accountability. Regarding the organization of information technology system, the successful implementation of the TABMIS system has helped accelerate the reform of the State management mechanism, providing timely information for management. However, this system also has certain limitations, therefore, it is necessary to continue to improve the TABMIS system, promote eGovernment implementation as one of the top objectives to reform the information system, supporting public disclosure of transparent financial reports, improving accountability of public sector financial reports. At the same time, the limitations on the quality of State audit are also issues that need to be concerned, specifically overlapping during implementation in audit plan and inspection, examination plans between State agencies have not been reviewed and thoroughly dealt with. The scope of audit activities of the State accounting is very small compared to the requirements of inspection, audit quality and audit progress, which is still far from the requirements of the State Audit Law, the audit report's content still focus on detecting error, not yet focused on the truthfulness of the data in the financial reports. Meanwhile, the Law on Access to Information and Decree 25, effective January 1, 2018, has been implemented to enable people to access public information in general and public financial information in particular, however, how effective these documents are at this point cannot be assessed.

Social and cultural factor: According to the International Transparency Organization, in 2016 Vietnam achieved 33/100 points, ranked $113 / 176$ on the global rankings, if compared to $31 / 100$ in the period of 2012 - 2015, this shows Vietnam has a remarkable effort in the fight against corruption of the State and society. In 2016, Vietnam issued many legal provisions to regulate this negative behavior, including: Approved the Law on Access to Information, completing the evaluation of 10 years of implementing the Law on Anti-Corruption and comprehensive implementation of the Anti-Corruption Law. Although the score increased slightly, but on a scale of $0-100$ of CPI, of which 0 is the highest corruption and 100 is very clean, the score of 33/100 this year shows that Vietnam has not created a groundbreaking change in the perception of corruption in the public sector and continues to be in the group of countries where corruption is considered to be serious.Considering the intellectual level, in recent years, the State has made great efforts in improving people's intellectual standards, expanding training schools, facilitating the development of communication, and a lot of information has been easily conveyed to People, legal documents are quickly widely known. The number of students studying finance and accounting has also increased, but focusing mainly on corporate accounting, public finance or public accounting has not been taught by many places, therefore, considering on a broad scale, the majority of people still do not understand much about public sector accounting, do not know the characteristics of accounting in our country and do not understand the content of indicators or meaning of data on financial reports. In general, people's awareness of their rolein term of control is quite limited, have no comment to the State budget revenues and expenditures, budget forecast, programs and projects during the year. It is still limited in the communication activities in order to improve people's knowledge and awareness of their role of master, as a result, it does not promote the monitoring role. Once the people's demand of accessing financial information increases, it becomes a driving force as well as a pressure on the State agencies in efforts to improve the quality of management and effective administrative activities, be able to provide financial reports which is reliable, public, transparent and meaningful explanation.

\section{RECOMMENDATIONS}

\section{Political system}

Strengthening support from law enforcement and legislative bodies: Continue to strengthen the role of law enforcement and legislative bodies in the implementation, management and legislative development. The National Assembly should focus on the nature of the problem and the practical requirements set forth in order to make appropriate legal adjustments so that the issued documents are not only valid on paper, but also go into the sense of implementation of each organization, each citizen, helps actualize the provisions of law into life

Increasing the supervision of the National Assembly: Continue to strengthen its supervisory role in checking the effectiveness of management and implementation of agencies. For the financial statements, 
the National Assembly needs to increase professional supervision capacity, limit the situation of reverence and avoidance, to build a reasonable organizational structure for supervision, investment in facilities and diversify types. The monitoring image on the National Assembly is still the main supervisor, it needs to go closely to the specific contents of each document to have objective assessments, and at the same time enhance the question to better understand the meaning of the data, to organize, the unit is aware of the accountability to the highest organ of the country and to show its responsibility in the daily work as well as the recording, processing and reporting.

Step by step promoting the activeness in work, overcoming the weakness and stagnation: The State should actively promote the movement of thinking innovation in the workplace, encourage initiative in work, be active and creative, set up an industrial style working environment, promote thinking and focus on results. Step by step decentralizing to local authorities to decide on revenues and expenditures, empowering officials to decide their own ways of working and take responsibility for the results, abolish the stagnation in work, informative, build a streamlined, efficient apparatus, avoiding the overlapping and bulky.

Strengthening the ownership role of the people: Gradually implement democratization in the political mechanism, promote the ownership and supervision of the people, to build an effective publicity process and get comments contribute as well as people's feedback before submitting to the National Assembly.

\section{Legal system}

Completing the document system on financial reports: Building a logical and streamlined document system, but ensuring that professional content is clearly expressed and unifying targets on the financial report for the entire public sector with the purpose that financial reporting not only makes sense to explain to high-level management agencies, but it is also easy to understand and make sense to other objects such as investors, foreign sponsors and peoples, step by step convert to accumulated accounting basis and completely applies to the entire public sector.

Finalizing and promulgating additional necessary legal documents for accountability of financial report: For documents of accountability, it is necessary to clearly define the responsibilities of officials, civil servants and stakeholders in each specific public relations, at the same time, clearly define corresponding powers and clarify responsibilities ofaccountability reports in the performance of official and civil servants. Some issues need to be clarified: what information to report, who reports, reports to whom and when to report. Measurement tools must be available to identify and analyze the information to be reported. Accountability must be associated with specific public relations such as for superior agencies, elected bodies, private sectors, social organizations, the public and related parties in each specific public relation.

Gradually improve and apply the model of State General Accounting: Continue to improve the legal framework and support the State Treasury in the implementation of the State General Accounting, focusing on the following issues: Ensuring focus on information for the management of unified State financial, organizing in line with the state financial decentralization mechanism, synchronously organizing the State accounting system, organizing the apparatus of the State General Accounting Department, strengthen inspection, control, audit and development of information technology application and public disclosure of State financial information.

Developing Vietnamese public sector accounting standards based on the use of International Public Sector Accounting Standards (IPSAS): The Ministry of Finance needs to establish a special Committee to carefully study the content of International Public Sector Accounting Standards, studying the specific of current Vietnam public sector in order to apply appropriate application of international public sector accounting standards in developing Vietnam's public accounting standards. 
Strengthening the level of law compliance of agencies, organizations and implementing units: Strengthening the management of cadres and administrative disciplines associated with the improvement of the moral qualities of officials and implementing units. Reviewing, supplementing and completing the internal rules, regulations, working procedures of their units, developing and organizing the implementation of specific programs and work plans based on the agencies' functions, assigned tasks, and at the same time, to aware the officials of discipline observance, administrative discipline, office culture and effectively use of working time, ensuring subordinates to follow leadership's direction and strictly in line with superiors'decisions.

Completing the process of applying the new public management model NPM: Step by step fully applying the new management model to replace the traditional public management model with the following contents: Promoting privatization for public services, restructuringthe business and administrative units, cumbersome State-owned Enterprises, ineffective operation into autonomous economic units, reforming the public services, civil servants, and decentralizing in management mechanism.

Complete coordination between departments: Develop an appropriate communication mechanism for local departments to receive information quickly, timely and simultaneously change in accordance with the new regulations of the law so that all public sector units are unified in how to implement and process, assist to collect data uniformly, financial reports are meaningful and provide useful information for decision making and accountability.

Issuing uniform standards for assessing the quality of financial report information: Develop a set of standards to assess the quality of financial report information focus on output results. This set of criteria helps accountants focusing on their work, while helping managers assess the credibility of the financial statements, limiting the time for re-checking, promoting efficiency and increasing confidence on data and meaning of financial statement accountability.

\section{Vocational education}

Strengthening empowerment, decentralization, facilitating the levels of task implementation: Stronger decentralization between the central government and local authorities and between local government levels is required, implementing the principle of "local self-management", allowing localities to reach their full potentials, deciding on issues related to their own work, avoiding the State's interference in the work of the State localities.

Improving the quality of State audit: Ensuring the independence of State accounting on all aspects; complete and build a system of guidelines and audit procedures for each type and field of audit; promote information technology in auditing activities, especially audit profession; strengthen training and retraining of qualified and experienced auditors; strengthen auditing and monitoring inspection during the audit process.

Improving organizational structure and management: Clearly defining functions, tasks, powers, responsibilities and relationships between organizations and agencies; resolutely remove organizations, unnec essary departmentsin organizations and apparatus; eliminating the overlap in functions and tasks of organizations, agencies and in each part of each organization and agency; strengthening the centralized and unified leadership and management role of the Central Government, and at the same time expanding the decentralization to localities to promote local dynamism, activeness, creativity and responsibility.

Upgrading the information technology system, enhancing and facilitating for people to access information: Developing infrastructure as a foundation for upgrading information systems, applying software of integrated information on budget revenues and expenditure management, budget forecast; develop modern software for recording and preparing financial statements; applying information technology in communication to update people timely with the latest information on the situation and 
efficiency of the State as well as new regulations of the law, that helps people to contribute ideas, demonstrating their ownership and supervision.

Improving the qualifications and capacity of accounting staff: Innovating training programs, university education, focusing on practical training, improving foreign language and computer skills of students and civil servants.

Completing the internal control system in the public sector: Promulgating regulations on internal control systemsin the public sector aimed at controlling, preventing risks, limiting waste, wrongly implementing regulations include activities in advance control, internal control and post-control as for businesses.

\section{Social culture}

Improving the moral qualities of civil servants and officials who implementing tasks, overcoming thoughts through loudspeakers, perfunctory: Issuing a set of ethical standards for officials to adjust workplace behavior. Applying thorough and systematic sanctions for corrupt, uncompromising acts of corruption; there are strictly regulations on violation of the law and an appropriate reward mechanism to encourage civil servants and officials to complete their work, towards the common interests of the organization. Besides, positive build up a culture of service for the benefit of the people and the country, aiming for high efficiency in work.

Improving people's intellectual level, thereby increasing the need for people to access financial information of the people: Strengthening propaganda and education to raise people's awareness about the roles and responsibilities of employers in participating in state management activities, firstly in the implementation of sacred voting rights, contributing to drafting legal documents and policies of the State, supervising the management and administration process of the authorities at all levels and in exercising the right to discuss and decide local and fundamental issues. The State should continue to improve the legal provisions on mechanisms and conditions for people to effectively implement the rights of citizens regarding the dismissal of deputies, complaints and denunciations.

\section{CONCLUSIONS}

Enhancement of accountability of public financial statements, strengthening public financial transparency is not only a positive solution to promote national economic development, reinforcing public trust but also an urgentrequirement of international economic relationships, therefore, this research to find factors affecting the accountability of financial statements in the public sector in Vietnam, measuring their impact is the goal that the authors aim to contribute for promoting the effectiveness of management and use of public resources, enhancethe public accountability, enable the public sector perform well as the key economic unit in the entire economy.

\section{ACKNOWLEDGMENT}

Doing this research, we express our gratitude to the experts, the managers who have supported in providing information as well as presenting valuable opinions, experiences in practice, and they also help us gain more knowledge to do this research by some interviews.

We also greatly appriciate the management agencies and colleagues for providing related materials to help us complete this research. We hope that this study will be valuable information for further research on public accountability reporting in Vietnam. 


\section{REFERENCES}

[1] Ahyaruddin, M. \& Akbar, R. (2016), The relationship between the use of a performance measurement system, organizational factors, accountability, and the performance of public sector organizations,Journal of Indonesian economy and business, Volume 31, No.1, 2016, 1-22.

[2] Vietnam Development Report 2010 (2009), Modern practices, Sponsor General Reportin the Consultancy Conference for Sponsor in Vietnam, Hanoi, December 3-4, 2009.

[3] Bovens, M (2007), Analysing of Assesing Accountability: A Conceptual Framwork, European Law Journal, vol.13, no.4, pp. 447-468.

[4] BuiHuyKhiem (2012), Researching the new public management model contributing to promoting administrative reform in the direction of effectiveness and efficiency, State Organization Journal No. $10 / 2012$.

[5] http://tcnn.vn/Plus.aspx/en/News/125/0/5020/0/6438/Nghien_cuu_mo_hinh_quan_ly_cong_moi_ gop_phan_day_manh_cai_cach_hanh_chinh_theo_huong_hieu_luc_hieu

[6] Bui Thi Ngoc Hien (2014),Improving accountability of the public sector in Vietnam.

[7] Bui Thi Ngoc Mai (2015),Responsibilities of heads of state administrative agencies, Doctoral thesis. National Academy of Public Administration.

[8] Cao Thi Cam Van (2016),Study the factors affecting the development of Vietnam's public accounting system in terms of applying international public accounting standards, Doctoral thesis, University of Economics Ho Chi Minh City, 2016.

[9] Cristina, S. N. et all (2013), The influence of environment factors on the evolution of Romania public accounting, Joural of business economics and management, ISSN 1611-1699, 09 May 2013.

[10] Duong Thi Binh and Do Thi Hue (2017),Accountability of State administrative agencies.

[11] http://tcdcpl.moj.gov.vn/qt/tintuc/Pages/xay-dung-phap-luat.aspx?ItemID=151

[12] Eivani, F. \& Nazari, K. \& Emami, M. (2012),Public accountability and government financial reporting. African journal of business management Volume 6 (29), pp. 8475-8482, 25 July, 2012.

[13] Goetz, A. M. \& R. Jenkins (2005), Re-inventing Accountability: Making Democracy Work for Human Development, International Political Economy Series, Basingstoke: Palgrave Macmillan.

[14] Greiling, D \& Spraul, K (2010),Accountability and the challenges of information disclosure, PAQ FALL 2010 .

[15] Haque, S \& Pathrannarakul, P (2013), The role of technology in enhancing transparency and accountability in public sector organizations of Pakistan, International journal of economics business and management study - IJENMS ISSN: 2226-4809; EISSN: 2304-6945. Volume 2, No. 1 (January, 2013) 20-24.

[16] Hulme D. \& Sanderatne N. (2008), The toothless and the muzzled: Public accountability, Public Expenditure Management and governance in Sri Lank, University of Manchester.

[17] Kewo, C. L. (2017), The influence of internal control implementation and managerial performance on financial accountability local government in Indonesia. International journal of economics and financial issues, 2017, 7 (1), 293-297, ISSN: 2146-4138. 
[18] Kluvers, R \& Tippet, J. (2011), The view of councilors and managers on accountability in local government: An empirical study in Australia, International journal of management, Volume 28, No.2, June 2011.

[19] Lepadatu, G. and Pirnau, M. (2009). Transparency in Financial Statements (IAS/IFRS). European Research Studies, [online] 12(1). Available at: https://www.ersj.eu/repec/ers/papers/09_1_p6.pdf [Accessed 29 Apr. 2018].

[20] Le Thi My Hanh (2014),Study the theory of transparency and accountability to apply to Vietnam's public sector accounting, Science and technology topics at school level. Economic University at Ho Chi Minh City.

[21] Le Thi Nha Trang (2012),Application of IPSAS Standards to the Vietnamese Government Accounting and Financial Statements, University of Tampere, Master Program in Public Finance Management.

[22] Le Tuyet Nhung (2014),Current State accounting regimes and perfect orientation to serve the goal of State financial reporting, Workshop of State Financial Statements, Ministry of Finance, Government Office, Quang Ninh, 2014.

[23] Munoz, L. A. \& Bolivar, M. P. R. (2015),Determining factors of transparency and accountability in local governments: A meta-analytic study, Lex Localis - Journal of local self-government.

[24] Nguyen Dinh Tho (2013),Methods of scientific research in business, in Financial Publishing House.

[25] Nguyen Thi Thu Hien (2015),Completing the financial report of the public sector in Vietnam.

[26] Nguyen Si Giao (2013), The conditions ensure the implementation of due diligence in the enforcement of public duties to contribute to anti-corruption, Scientific topics at the grassroots level. Institute of Inspectorate Science.

[27] Ouda, H. (2004),Basis Requirements Model For Successful Implementation Of Accounting In The Public Sector, International Consortium on Governmental Financial Management, Public Fund Digest Volume IV, No.1.

[28] Reginato, E. (2010),Accountability perspectives in Italian municipality accounting systems: The gap between regulations and practices, PAQ WINTER 2010.

[29] Salawu, R. O \& Agbeja, O. (2007), Auditing and accountability mechanism in the public sector, The international journal of applied economics and finance 1 (1): 45-54, 2007 ISSN 1991-0886.

[30] Truong A Binh (2017), Researching the factors affecting the accountability of financial report in Vietnam public sector, Master thesis, University of Economics Ho Chi Minh City, 2017.

[31]Zhang (2005),Environmental Factor in China's Financial Accounting Development since 1949, The Erasmus University, Rotterdam.

Received on February 1st, 2019

Accepted on March 25th, 2019 